Correspondence: Alberto Cukier, Pulmonary Division, Instituto do Coracão, Av. Dr. Enéas de Carvalho Aguiar, 44, Quinto andar, CEP 05403-900, São Paulo, SP, Brazil. E-mail: pnealberto@incor.usp.br

Received: June 262014 | Accepted: June 302014

Conflict of interest: Disclosures can be found alongside the online version of this article at erj.ersjournals.com

Acknowledgements: The authors thank C.S. Redigolo (Dept of Public Politics and Public Health, Federal University of São Paulo, Santos, Brazil) and R.A. de Oliveira Figueiredo (Faculty of Public Health, University of São Paulo, São Paulo, Brazil) for assistance with the statistical analysis.

\title{
References
}

Dias-Júnior SA, Reis M, de Carvalho-Pinto RM, et al. Effects of weight loss on asthma control in obese patients with severe asthma. Eur Respir J 2014; 43: 1368-1377.

2 Bland JM, Altman DG. Comparisons against baseline within randomised groups are often used and can be highly misleading. Trials 2011; 12: 264.

3 Diggle PJ, Heagerty PJ, Liang K, et al. Analysis of Longitudinal Data. 2nd Edn. Oxford, Oxford Science Publications, 2002.

4 Chow S, Liu J. Design and analysis of clinical trials: concepts and methodologies. 3rd Edn. New York, John Wiley \& Sons Inc., 2014.

\section{International European Respiratory Society/American Thoracic Society guidelines on severe asthma}

\section{To the Editor:}

In their recent paper on severe asthma, CHUNG et al. [1] proposed excellent guidelines concerning this difficult topic. We commend them for having used the Grading of Recommendations Assessment, Development and Evaluation approach to study the evidence for the management of the disease. This method has been recognised to be of great importance for guideline development.

The authors have reviewed recent statements on severe asthma $[2,3]$ and agree upon most of the proposals discussed. However, these statements differ from those in the paper presented to the World Health Organisation [3]: they did not consider untreated asthma, probably because it is thought that this is a problem only for developing countries. We do not agree with this proposal; all patients in the world should have access to treatment to reduce exacerbations and deaths, and recommendations should be made for all patients. Moreover, this statement does not accord with the recent findings in developed countries. These findings have recently been widely publicised in the National Review of Asthma Deaths (NRAD) in the UK, run by a consortium of asthma professionals and patients, and led by the Royal College of Physicians [4]. This review looked into the circumstances surrounding deaths from asthma between 2012 and 2013. The NRAD was commissioned by National Health Service (NHS) England, NHS Wales, the Health and Social Care division of the Scottish government, the Department of Health, and the Northern Ireland Department of Health, Social Services and Public Safety. It was found that most asthma deaths were related to undertreatment or to a lack of controller treatment. We strongly think that untreated asthma must be considered a potential form of severe asthma, as people with asthma may experience severe asthma symptoms. We think that there should not be an over-reliance on mild asthma in untreated patients with a diagnosis of asthma.

In the recent document on airways integrated care pathways of the Action Plan B3 of the European Innovation Partnership on Active and Healthy Ageing [5], severe asthma is proposed to be considered in untreated patients. We think that patients with under-treatment should be added to this category, as they were found to be the highest risk group for asthma death [4]. 
Jean Bousquet ${ }^{1,2}$, Nikolai Khaltaev ${ }^{3}$, Alvaro Cruz ${ }^{3,4}$, Arzu Yorgancioglu ${ }^{3,5}$ and Alexander Chuchalin ${ }^{3,6}$

${ }^{1}$ University Hospital, Montpellier, France. ${ }^{2}$ MACVIA-LR, Contre les Maladies Chroniques pour un Vieillissement Actif en Languedoc Roussillon, European Innovation Partnership on Active and Healthy Ageing Reference Site, Montpellier, France. ${ }^{3}$ GARD, Geneva, Switzerland. ${ }^{4}$ ProAR - Nucleo de Excelencia em Asma, Federal University of Bahia, Salvador, Brasil. ${ }^{5}$ Celal Bayar University Dept of Pulmonology, Manisa, Turkey. ${ }^{6}$ Pulmonolory Research Institute FMBA, Moscow, Russia.

Correspondence: Jean Bousquet, University Hospital, Montpellier, France. E-mail: jean.bousquet@orange.fr

Received: June 042014 | Accepted: June 122014

Conflict of interest: Disclosures can be found alongside the online version of this article at erj.ersjournals.com

\section{References}

1 Chung KF, Wenzel SE, Brozek JL, et al. International ERS/ATS guidelines on definition, evaluation and treatment of severe asthma. Eur Respir J 2014; 43: 343-373.

2 Bel EH, Sousa A, Fleming L, et al. Diagnosis and definition of severe refractory asthma: an international consensus statement from the Innovative Medicine Initiative (IMI). Thorax 2011; 66: 910-917.

3 Bousquet J, Mantzouranis E, Cruz AA, et al. Uniform definition of asthma severity, control, and exacerbations: document presented for the World Health Organization Consultation on Severe Asthma. J Allergy Clin Immunol 2010; 126: 926-938.

4 Royal College of Physicians. National Review of Asthma Deaths. www.rcplondon.ac.uk/projects/national-reviewasthma-deaths Date last accessed: May 31, 2014. Date last updated: May 27, 2014.

5 Bousquet J, Addis A, Adcock I, et al. Integrated care pathways for airway diseases (AIRWAYS-ICPs). Eur Respir $J$ 2014; 44: 304-323.

Eur Respir J 2014; 44: 1377-1378 | DOI: 10.1183/09031936.00102714 | Copyright @ERS 2014

\section{From the authors:}

We thank J. Bousquet and colleagues for their concerns regarding exclusion of "untreated asthma" as a form of severe asthma, with respect to the recently published international European Respiratory Society (ERS)/American Thoracic Society (ATS) guidelines on severe asthma [1].

We do recognise this category of untreated asthma and agree that untreated asthma may result in serious exacerbations of disease and death, an issue that is not confined to developing countries alone. Indeed, everywhere in the world, untreated asthma can result from lack of access to medical care but can also result not only from nonadherence to therapy or of inadequately treated asthma. As emphasised in the ERS/ATS guideline definitions, these issues should to be addressed before consideration of the diagnosis of severe asthma. As mentioned by the correspondents, the recent report of the UK National Review of Asthma Deaths pointed to under-treatment or lack of controller treatment, from nonadherence or inadequately treated asthma, which represents degrees of "untreated" asthma, evident in a country where everyone has access to medical care. The approach here is to identify the asthmatics who are at risk of dying from asthma and make sure that their asthma is indeed properly diagnosed and categorised, and treated appropriately. As our correspondents are aware, this is no mean task and is even near-impossible in developing countries where the healthcare infrastructure is not as well developed or funded.

We are fully aware of the World Health Organization (WHO) consultation document [2], not least, because several members of our ERS/ATS guideline task force have been involved in it. Untreated asthma could not be included within our severe asthma definition because our definition requires that patients receive or have received "appropriate/guidelines-based" therapy for asthma. While we agree that untreated or undertreated asthma predisposes a subgroup of these patients to severe and life-threatening exacerbations, we also believe that the introduction of even modest doses of corticosteroids will dramatically decrease their risk of severe asthma exacerbations. Thus, the ERS/ATS guidelines define severe asthma as "asthma that requires treatment with high dose inhaled corticosteroids plus a second controller (and/or systemic corticosteroids) to prevent it from becoming 'uncontrolled' or which remains 'uncontrolled' despite this therapy". These patients represent a poorly understood and poorly therapy-responsive population that is distinct from under-treated or untreated asthma.

The WHO consultation document recognised three categories of asthma that were considered severe on the basis of symptoms, control of asthma and risks, without consideration of the therapy taken by the patient. These categories are 1) untreated severe asthma, 2) difficult-to-treat severe asthma and 3) treatmentresistant severe asthma, with which we are in full agreement. We agree that, from the global standpoint, untreated severe asthma needs to be recognised as it is a problem that should be remediable through the 